\title{
Assessing Resilience of Urban Critical Infrastructure Networks: A Case Study of Ahvaz, Iran
}

\author{
Hadi Alizadeh ${ }^{1}$ and Ayyoob Sharifi ${ }^{2,3,4, *(0)}$ \\ 1 Geography and Urban Planning, Shahid Chamran University of Ahvaz, Ahvaz 6135783151, Iran; \\ h-alizadeh@phdstu.scu.ac.ir \\ 2 Graduate School of Humanities and Social Sciences, Hiroshima University, \\ Higashi-Hiroshima 739-8530, Japan \\ 3 Graduate School of Advanced Science and Engineering, Hiroshima University, \\ Higashi-Hiroshima 739-8530, Japan \\ 4 Network for Education and Research on Peace and Sustainability (NERPS), Hiroshima University, \\ Higashi-Hiroshima 739-8530, Japan \\ * Correspondence: sharifi@hiroshima-u.ac.jp; Tel.: +81-82-424-6826
}

Received: 16 April 2020; Accepted: 1 May 2020; Published: 2 May 2020

\begin{abstract}
Cities around the world increasingly recognize the need to build on their resilience to deal with the converging forces of urbanization and climate change. Given the significance of critical infrastructure for maintaining quality of life in cities, improving their resilience is of high importance to planners and policy makers. The main purpose of this study is to spatially analyze the resilience of water, electricity, and gas critical infrastructure networks in Ahvaz, a major Iranian city that has been hit by various disastrous events over the past few years. Towards this goal, we first conducted a two-round Delphi survey to identify criteria that can be used for determining resilience of critical infrastructure networks across different parts of the city. The selected criteria that were used for spatial analysis are related to the physical texture, the design pattern, and the scale of service provision of the critical infrastructure networks. Results showed that, overall, critical infrastructure networks in Ahvaz do not perform well against the measurement criteria. This is specially the case in Regions 1, 2, 4 , and 6 , which are characterized by issues such as old and centralized infrastructure networks and high levels of population density. The study highlights the need to make improvements in terms of the robustness, redundancy, and flexibility of the critical infrastructure networks in the city.
\end{abstract}

Keywords: critical infrastructure; resilience; spatial analysis; redundancy; robustness; flexibility; vulnerability

\section{Introduction}

Cities have traditionally been hubs of innovation and economic growth and have played major roles in the regional and national development processes. As urbanization trends continue to grow, cities around the world are receiving even more traction. However, while cities are hubs of opportunities, given the high concentration of people and resources in them, they are also susceptible to a wide array of risks and hazards and need to build on their resilience [1,2]. Although the concept of resilience has a long history, it was not introduced to the urban studies field until the late years of the 1990s. Since then, it has been widely used and is expected to get even more attention since the planet is rapidly urbanizing and the frequency and intensity of disastrous events are expected to increase due to climate change [3]. Although there is no universal definition for resilience, in the context of urban infrastructure, it is often linked to capacities related to mitigation and absorption of shocks and rapid recovery to pre-disaster conditions [4,5]. Critical infrastructures are essential components of cities 
and their continuous functionality is crucial for maintaining acceptable levels of quality of life [6]. Accordingly, enhancing resilience of critical infrastructure systems to natural disaster events (e.g., earthquakes and floods) as well as man-made events (e.g., terrorist attacks) is of significant importance. It is argued that critical infrastructure systems should be robust enough to resist failures and/or rapidly gain back their functionality in case of partial failures [6,7].

It is worth noting that the concept of resilience goes beyond just robustness and recovery, which are mainly related to the technical and physical characteristics of the critical infrastructure. In fact, the need to acknowledge soft characteristics related to issues such as economy, social learning, and adaptation has also been discussed in recent years $[4,8,9]$. Despite this, the traditional conceptualization that is mainly related to technical and physical aspects is still dominant in the context of critical infrastructure systems. For instance, a frequently used definition provided by the United Nations International Strategy for Disaster Reduction (UNISDR) states that resilience is "the ability of a system, community or society exposed to hazards to resist, absorb, accommodate to and recover from the effects of a hazard in a timely and efficient manner, including through the preservation and restoration of its essential basic structures and functions" [10]. Following this definition, resilient critical infrastructure systems should be able to resist and absorb shocks to minimize the potential damage and facilitate timely return to pre-disruption functionality levels [11,12].

Improving critical infrastructure resilience is particularly important in developing countries since they often lack appropriate planning and adaptive capacities to absorb and recover from disasters [13,14]. Iran is no exception in this regard. It is a country exposed to a wide range of adverse events, ranging from earthquakes to major floods $[15,16]$. Despite this, there is still a lack of research on critical infrastructure resilience in Iranian cities. Against this backdrop and as a preliminary effort toward filling this gap, the main purpose of this research is to spatially analyze the resilience of critical infrastructure networks in Ahvaz, a major metropolitan area located in southwest Iran. Ahvaz is a geopolitically important city considering its proximity to the oil-rich part of the country. In the recent years it has been hit by various climate-induced events such as dust storms, extreme heat events, and floods. Due to various factors, such as the aged urban infrastructure, these events have caused major problems for the city residents with some repercussions at the national level (since the city is the capital city of the oil-rich Khuzestan province). For instance, in 2017, the dust storm that lasted two weeks resulted in major black- and brownouts that also affected the city's water network, given the water-energy nexus. As a consequence, the normal functionality of major sectors and services such as hospitals and governmental departments was disrupted and the quality of life was significantly undermined [17]. Results of this study can be used to inform planners and decision makers of the areas that need further attention and should be prioritized in efforts toward improving urban resilience.

The study is structured as follows: a brief literature review is presented in the next section. Section 3 elaborates on methods and materials. Results of spatial analysis related to water, electricity, and gas networks are reported in Section 4. Finally, Section 5 concludes the study by discussing the findings and providing some policy recommendations.

\section{Literature Review}

Here, we first provide a brief overview of resilience and its underlying characteristics and then explain how critical infrastructure resilience is defined in the literature.

While the concept of resilience has a long tradition in disciplines such as physics, psychology, and, ecology, it was not until the late years of the 1990s that scholars started applying it to urban research and practice $[18,19]$. In physics and psychology, the emphasis is on the absorption and recovery capacities of an object and/or system. In other words, characteristics such as resistance and rapid recovery have been traditionally emphasized [20-23]. In the field of ecology, from which the 'urban studies' field has borrowed the concept of resilience, the concept is broadened to include other capacities such as planning and adaptation [24]. 
Disaster risk management in the field of urban studies was originally mainly focused on vulnerability reduction. Despite linkages to resilience, vulnerability is a different term and refers to susceptibility to disruption and loss. It is, therefore, mostly a static concept. In contrast, resilience is a dynamic concept and can be used to explore how vulnerabilities change over time [25-27]. Urban resilience is, however, still a contested concept and there is no universally accepted definition for it [28]. Similar to the ecological conceptualization of resilience, three major approaches towards defining urban resilience can be distinguished in the literature: engineering, ecological, and socio-ecological or adaptive [29]. The engineering approach emphasizes the robustness and stability of the urban system to minimize the likelihood of disruption and/or collapse. In case disruptions happen, engineering resilience advocates taking necessary measures to facilitate rapid recovery to return to the pre-disruption equilibrium state $[29,30]$. Accordingly, engineering resilience entails a static approach towards urban resilience and is likely to fail to take account of the dynamics of the urban system. In contrast, the ecological approach towards defining urban resilience emphasizes tenacity of the system and acknowledges that future uncertainties and constantly changing urban dynamics make it difficult, if not impossible, to have overreliance on robustness and stability characteristics. Instead, it calls for improving the absorption capacities to minimize disturbance and retain the basic structural functionality of the system. Further, depending on factors such as the initial structural robustness of the system, the severity of the disturbance, and the system's ability to absorb the initial shocks, it may not be possible to return to the pre-disturbance equilibrium state during the recovery process. Instead, the system may enter a new equilibrium condition or set of conditions; this often involves not only building back, but also building better. This is in line with Holling's conceptualization of resilience [24]. The last and most recent approach towards defining urban resilience builds on the ecological approach by making better recognition of the complexities of cities as dynamic socio-ecological systems. By recognizing the fact that future uncertainties may make it difficult to reach equilibrium state(s), the socio-ecological (adaptive) approach highlights the significance of adaptation and living with risk [30]. This approach is particularly useful in an era that is characterized by significant uncertainties that are caused by multiple forces such as climate change and rapid urbanization. Keeping these various approaches in mind, a commonly-used definition of urban resilience is the ability to "plan and prepare for, absorb, recover from, and more successfully adapt" to shocks and adverse events in cities [31]. What is obvious from this definition is that resilience is not just an end goal. Instead, it is a property of the urban system that involves different processes and feedbacks across multiple temporal and spatial scales and various dimensions of the urban system.

To operationalize urban resilience, it has been linked to various characteristics such as preparedness, robustness, reliability, redundancy, resourcefulness, rapidity, flexibility, recoverability, and adaptability $[27,30]$. Preparedness refers to actions that need to be taken proactively and before the occurrence of the disruptive event in order to reduce potential damage and ensure adequate capacity is available for timely recovery [32,33]. Robustness is a characteristic that indicates the physical strength and resistance of a system [26,34]. Reliability is closely related to robustness and refers to the likelihood of a system maintaining its functionality during adverse events [35]. Redundancy refers to the presence of spare components in the system that can compensate for the failing components and ensure continuous functionality of the system $[35,36]$. Resourcefulness indicates the availability of various types of human, financial, and infrastructural resources during planning, absorption, and recovery stages [37]). Rapidity refers to the recovery speed and is important to minimize the duration of reduced functionality of the system [38]). Flexibility is a characteristic that entails having the capacity to make adjustments to the regular operations of the system in order to ensure effective functionality during disastrous events [39]. Recoverability indicates the capacity to return to pre-disaster equilibrium conditions in a timely manner $[40,41]$. Finally, adaptability is a characteristic that emphasizes the ability to learn from the adverse event and improve the capacity to better respond to potential future shocks [42,43]. In the following sections, we try to explain the resilience of the critical infrastructure networks by referring to these characteristics. 
To the best knowledge of the authors, there is still no research on the resilience of critical infrastructure networks in Iran. The research is also limited globally. Existing research is mainly focused on the physical structure (i.e., preparedness and robustness) of critical infrastructures and does not address the network structure specifically. In their study of infrastructure resilience in the Pearl River Delta city clusters of China, $\mathrm{Ng}$, et al. [44] developed an integrated framework to manage and improve the resilience of infrastructure systems. Elsewhere, Govindarajulu [45] examined the resilience of critical infrastructure systems in five major Indian cities and emphasized institutional and financial challenges. Drawing on publicly available municipal financial data and reports prepared by urban local bodies, he evaluated measures taken to improve resilience and found out that there is a lack of proper actions and investment in critical infrastructure resilience. Having a more physical focus, Yang, et al. [46] proposed a framework for analyzing resilience of interconnected infrastructure systems. They applied this framework to the stormwater drainage and road transport systems of Hong Kong and demonstrated how vulnerabilities in critical infrastructure networks may lead to significant cascading effects. Having a similar focus on the interconnectivity of critical infrastructure networks and its implications for resilience, Nazarnia, et al. [47] examined the resilience of water and electricity infrastructure networks in Bhaktapur, Nepal, using a network analysis framework. They confirmed the close interlinkages between these two infrastructure systems and shed more lights on potential absorption and recovery patterns in the face of disruptive events.

Overall, there is a consensus in the literature that critical infrastructure systems are fundamental components of cities and improving their resilience is essential for maintaining effective urban functionality $[48,49]$. In fact, any disruptions in the functionality of critical infrastructures can have significant economic, social, health and well-being, security, and environmental ramifications [50]. Given their significance, it is even argued that the vulnerability of critical infrastructure may undermine efforts aimed at achieving urban sustainability [51].

Despite the significance of critical infrastructure resilience, until about one decade ago the focus was mainly on infrastructure resistance and not resilience. The European Commission (EC) and the United States Department of Homeland Security were amongst the leading entities that developed plans for critical infrastructure protection through, respectively, "The 2008 directive on the identification and designation of European critical infrastructures and the assessment of the need to improve their protection [52], and the "National Infrastructure Protection Plan" [53].

A paradigm shift from critical infrastructure protection to critical infrastructure resilience has occurred in recent years $[4,9]$. The main reason behind this paradigm shift is the increasing recognition that, due to the increase in the uncertainty, frequency, and intensity of extreme events, physical approaches may not be sufficient. In fact, it is now increasingly acknowledged that not all risks are predictable and resilience thinking is essential to deal with emergent risks [9]. In line with this, several scholars have made efforts to develop frameworks for measuring critical infrastructure resilience. For instance, Ouyang, et al. [54] suggested a three-stage framework that visualizes the typical changes in the performance level of critical infrastructure in the aftermath of an adverse event (Figure 1).

The framework presented in Figure 1 is well aligned with the engineering and ecological definitions of resilience that were discussed earlier. Three major stages, namely, disaster resistance and prevention, disaster absorption, and disaster recovery, can be distinguished [54]. It can be seen that planning/preparation measures taken before shock occurrence $\left(t_{0}\right)$, in combination with absorption measures (taken between $t_{0}$ and $t_{1}$ time epochs) can contribute to reducing complete performance loss. After the system reaches its minimum performance level at $t_{1}$, overall assessment of the situation should be done (between $t_{1}$ and $t_{2}$ ) and plans should be made to rapidly return back to pre-shock performance levels at $t_{\mathrm{E}}$. A similar three-stage framework has also been proposed by Petit, et al. [55]. In a more recent effort, Rehak, Senovsky and Slivkova [41] have proposed a framework that includes organizational dimensions, in addition to technical ones. Specifically, they have proposed a critical infrastructure resilience cycle (Figure 2) that includes physical/technical characteristics (e.g., preparedness, robustness, 
rapidity, and recoverability) as well as organizational characteristics (e.g., adaptability). This indicates a gradual shift from purely engineering-based approaches to approaches that also recognize the importance of adaptation [41].

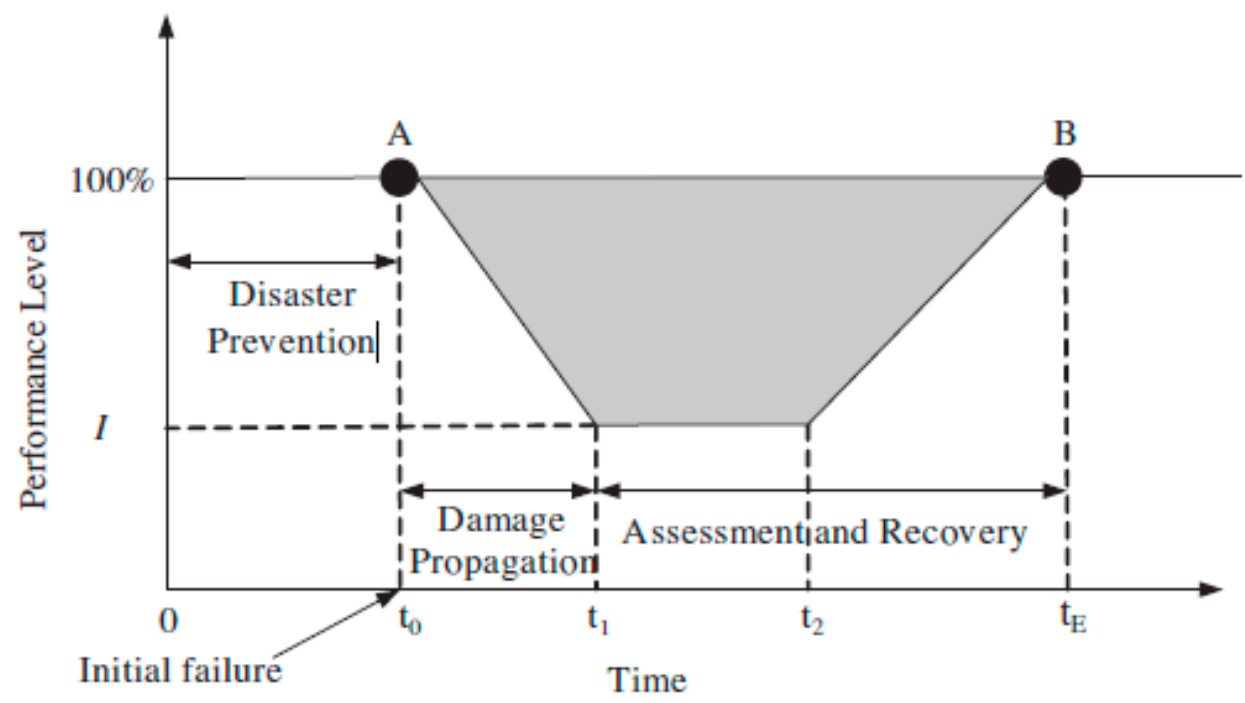

Figure 1. Changes in the performance level of typical critical infrastructure in the aftermath of an adverse event ([54]).

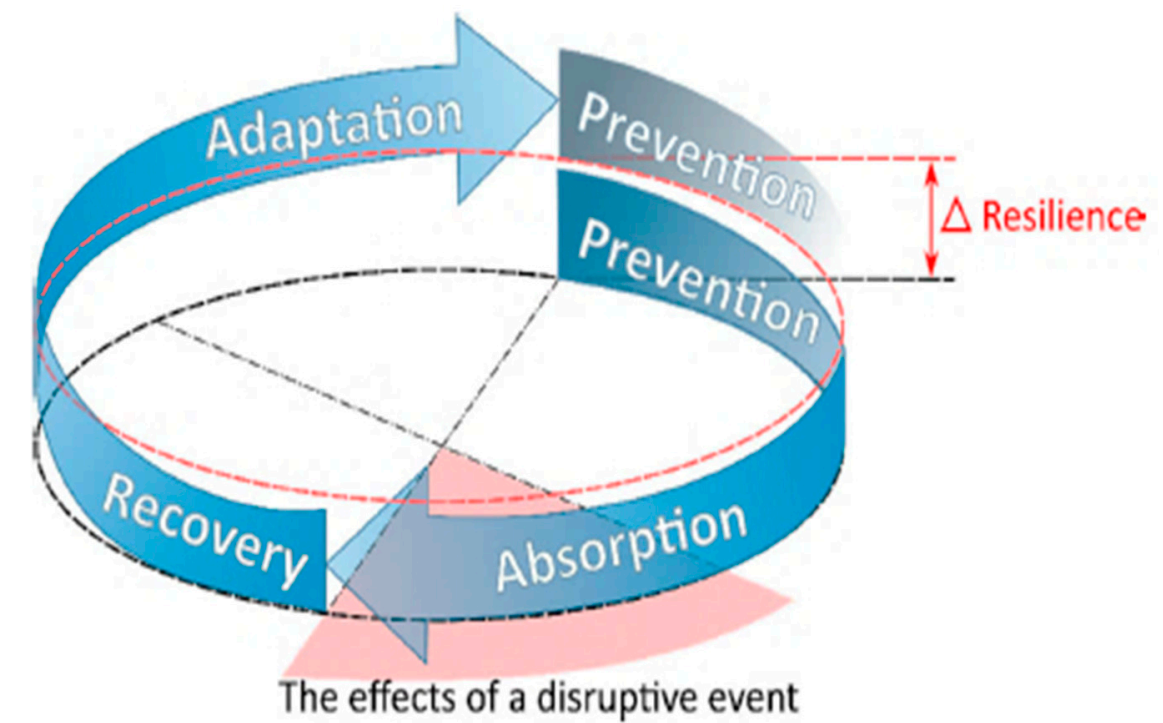

Figure 2. Critical infrastructure resilience cycle based on Rehak, Senovsky and Slivkova [41].

Four major stages can be distinguished from Figure 2. The first phase is prevention and is aimed at reducing exposure and vulnerability to potential disruptive events. In case some failures occur, a resilient infrastructure system should be robust enough and have adequate absorption capacities to minimize the functionality loss. Despite this, some functionality loss may occur due to the severity of the shock or the vulnerability of the system. In that case, the system should be able to bounce back to equilibrium conditions during the recovery stage. Finally, the adaptation stage involves considering the disruptive event as an opportunity to improve the overall performance of the system (bounce forward) in order to perform better against potential future shocks [41]. Regarding the resilience characteristics for critical infrastructure, similar to what was earlier discussed regarding the general approaches to resilience, various characteristics such as robustness, redundancy, recoverability, and adaptability have been mentioned in the literature [12,56]. Table 1 provides a summary of 
definitions used for resilience of water, gas and electricity infrastructure systems. It also shows how these definitions are linked to different resilience stages and characteristics. It can be observed that 'planning', 'absorption', and 'recovery' are stages that have received more attention. Other recurring characteristics are 'robustness', 'reliability', 'absorption', and 'rapidity'. Overall, research on critical infrastructure resilience is mainly focused on physical and technical aspects of resilience.

Table 1. Major stages and characteristics used for defining critical infrastructure resilience.

\begin{tabular}{|c|c|c|c|}
\hline \multicolumn{4}{|c|}{ Water Infrastructure } \\
\hline References & Resilience Definition & Related Stage(s) & Related Characteristic(s) \\
\hline [57] & $\begin{array}{l}\text { The "ability of a system to reduce the chances of shock, to absorb } \\
\text { such a shock if it occurs, and to recovery quickly after a shock". }\end{array}$ & Planning, absorption, recovery & Preparedness, robustness, rapidity \\
\hline [59] & $\begin{array}{l}\text { The ability in "the four infrastructural qualities: robustness, } \\
\text { redundancy, resourcefulness and rapidity". }\end{array}$ & NA & $\begin{array}{l}\text { Robustness, redundancy, } \\
\text { resourcefulness, and rapidity }\end{array}$ \\
\hline [61] & $\begin{array}{l}\text { "The residual functionality of the system in the aftermath of a } \\
\text { disaster (i.e. robustness) and the system's swiftness in bouncing } \\
\text { back to a normal level of functionality (i.e. recovery rapidity)". }\end{array}$ & Absorption, recovery & Robustness, reliability, rapidity \\
\hline \multicolumn{4}{|c|}{ Gas infrastructure } \\
\hline References & Resilience definition & & Related stages and characteristics \\
\hline [64] & "Ability to resist, re stabilize, rebuild, and reconfigure". & Absorption, recovery & Robustness, flexibility \\
\hline [65] & Ability to have robust and reliable structures. & Absorption & Robustness, reliability \\
\hline \multicolumn{4}{|c|}{ Electricity infrastructure } \\
\hline References & Resilience definition & & Related stages and characteristics \\
\hline$[48,66]$ & $\begin{array}{l}\text { The "capacity of system includes absorptive capacity, adaptive } \\
\text { capacity and restorative capacity". }\end{array}$ & Absorption, recovery, adaptation & Robustness, rapidity, adaptability \\
\hline [67] & $\begin{array}{l}\text { The "capacity for a system to withstand, absorb, and recover from } \\
\text { a disruption". }\end{array}$ & Planning, absorption, recovery & $\begin{array}{l}\text { Preparedness, robustness, } \\
\text { reliability, rapidity }\end{array}$ \\
\hline [68] & $\begin{array}{l}\text { "Ability to resist (prevent and withstand) multiple possible hazards, } \\
\text { absorb the initial damage, and recover to normal operation". }\end{array}$ & Planning, absorption, recovery & $\begin{array}{l}\text { Preparedness, robustness, } \\
\text { reliability, rapidity }\end{array}$ \\
\hline [69] & $\begin{array}{l}\text { "The ability of a system to anticipate and withstand external shocks, } \\
\text { bounce back to its pre-shock state as quickly as possible and adapt } \\
\text { to be better prepared to future catastrophic events". }\end{array}$ & $\begin{array}{l}\text { Planning, absorption, } \\
\text { recovery, adaptation }\end{array}$ & $\begin{array}{l}\text { Preparedness, robustness, } \\
\text { reliability, rapidity }\end{array}$ \\
\hline
\end{tabular}

\section{Case Study Introduction and Methods}

As discussed in the previous section, there is still a lack of research on the resilience of criticial infrastructure networks, particularly in the Iranian context. As a step toward filling this gap, in this study, we focus on Ahvaz, a major Iranian city that has experienced various disastrous events in the past few years. In this section, we first introduce the case study area and then explain the research methods and materials.

\subsection{Case Study Area}

Ahvaz, the capital city of Khuzestan province, is located at $31^{\circ} 20^{\prime}$ north latitude and $48^{\circ} 40^{\prime}$ east longitude. It is the second-largest city in Iran (in terms of area) after Tehran, covering about $215 \mathrm{~km}^{2}$ (Figure 3), and straddles the Karun River, which is one of the major rivers in the country. Located in an oil-rich province that borders Iraq and Kuwait, the city has an important geopolitical position [17,71]. The location of the city is shown in Figure 3. Ahvaz is divided into eight municipal regions as shown in Figure 3. Some statistics related to these districts is shown in Table 2. 


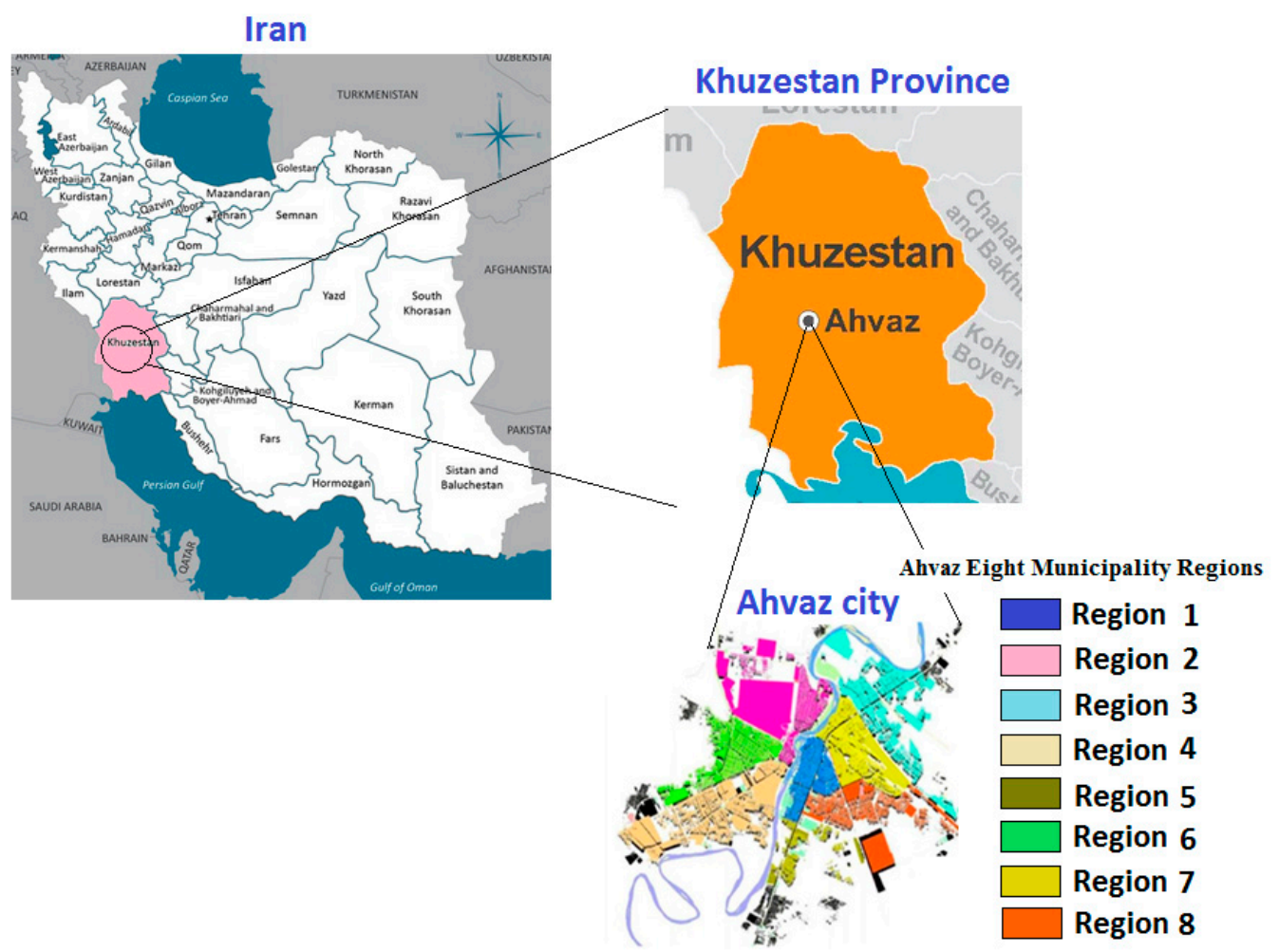

Figure 3. Location of the case study area [72-74].

Table 2. Statistics related to the eight municipal regions of Ahvaz [72].

\begin{tabular}{ccc}
\hline Region & Area (ha) & Approximate Population \\
\hline No.1 & 1103 & 141,000 \\
No.2 & 2913 & 108,000 \\
No.3 & 3181 & 178,000 \\
No.4 & 3816 & 155,000 \\
No.5 & 1349 & 107,000 \\
No.6 & 2976 & 185,000 \\
No.7 & 1718 & 148,000 \\
No.8 & 3098 & 194,000 \\
Total & 20,154 & $1,216,000$ \\
\hline
\end{tabular}

During the past few years, the city has experienced several natural disasters that have affected the functionality of its critical infrastructures. These disaster events have particularly affected the water/wastewater and power infrastructure systems. Located on a flat plain, and lacking a planned drainage system, Ahvaz is vulnerable to moderate to intensive rainfall events. According to the managing director of the Water and Wastewater Engineering Company of Ahvaz, of the total $2400 \mathrm{Km}$ drainage infrastructure network of the city, about $1100 \mathrm{Km}$ is aged and poorly maintained (https://www.tasnimnews.com/fa/news/1398/09/06/2146893/). In addition, the city's proximity to the Karun River makes it more vulnerable to fluvial flooding. As a result, the city is vulnerable to flooding. For instance, following the major flooding that occurred in March-April 2019, due to the overflow of Karun River, about $70 \%$ of the city's water and transportation infrastructure networks was seriously affected (https://www.irna.ir/news/83612665/; https://news.nww.ir/archive/ID/17044) (see Figure 4). In fact, restoring the functionality of the water distribution network and water treatment plants alone took about one moth [17]. 


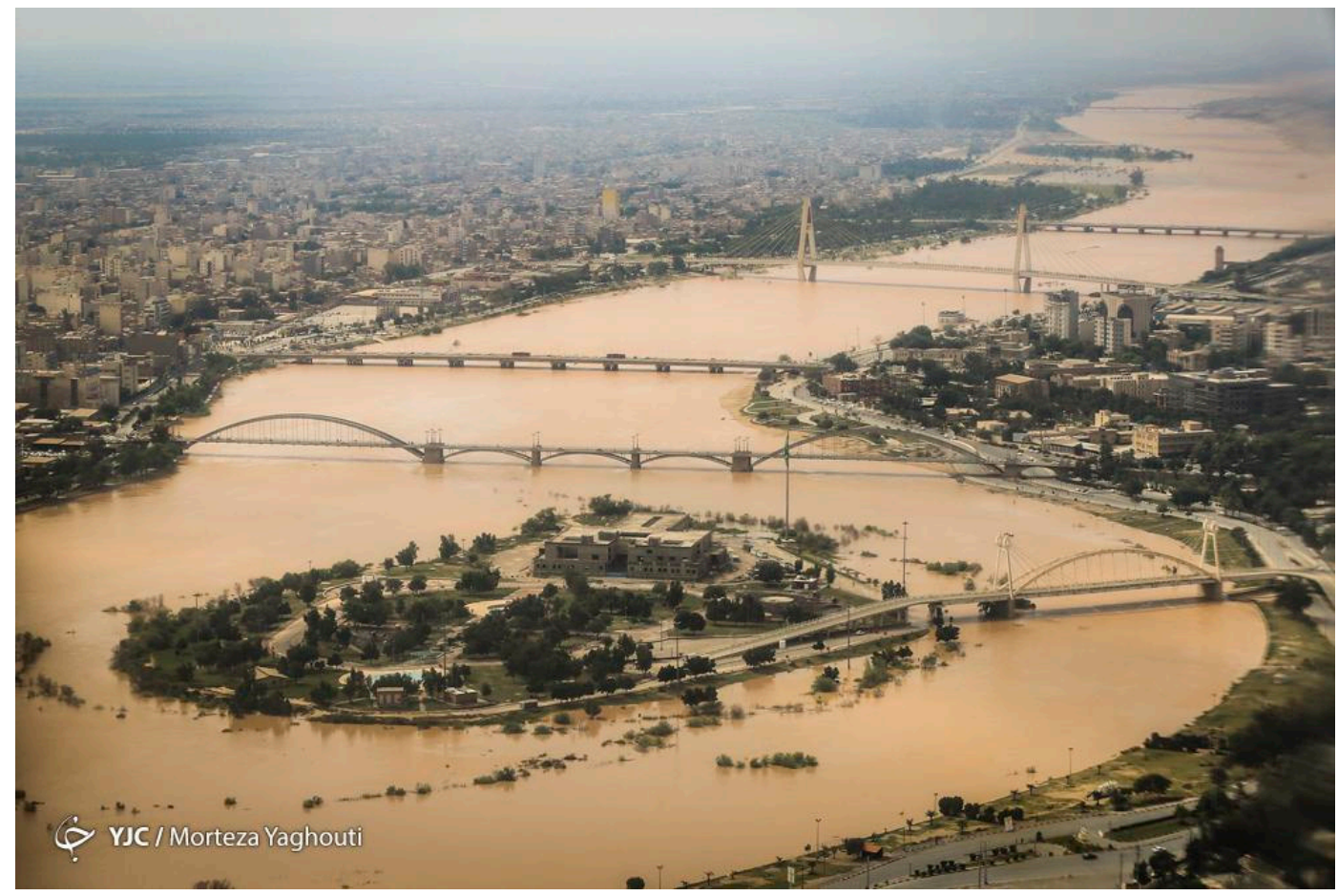

Figure 4. A scene from the March 2019 flooding event (Source: https://www.yjc.ir/fa/news/7177872/).

The city is also exposed to other adverse events such as major wind and dust storms and lightning strikes that occur several times every year and have major impacts on the critical infrastructure system (Figure 5). These types of adverse events impact the electricity infrastructure networks directly and may also disrupt other networks through cascading effects. For instance, in 2017, a major dust storm disrupted the operation of the power grid, leading to major blackouts across the city. There is also evidence showing that damages caused by dust storms and lightning strikes have caused blackouts in large parts of the city, affecting up to $60 \%$ of the residents [17]. According to the managing director of the city's grid management company, wind and dust storms have caused damage equivalent to about 333 KUSD in 2017. He estimates that 30 times this amount is needed for proper upgrading and maintenance of the city's power network in order to increase its resilience to future events (https://www.irna.ir/news/82758332/). It is worth mentioning that, given the energy-water nexus, and also the energy dependence of other infrastructure systems, any disruptions in the electricity network are also likely to disrupt other networks too. This indicates the likelihood of serious domino effects due to disruption in particular types of the critical infrastructure.

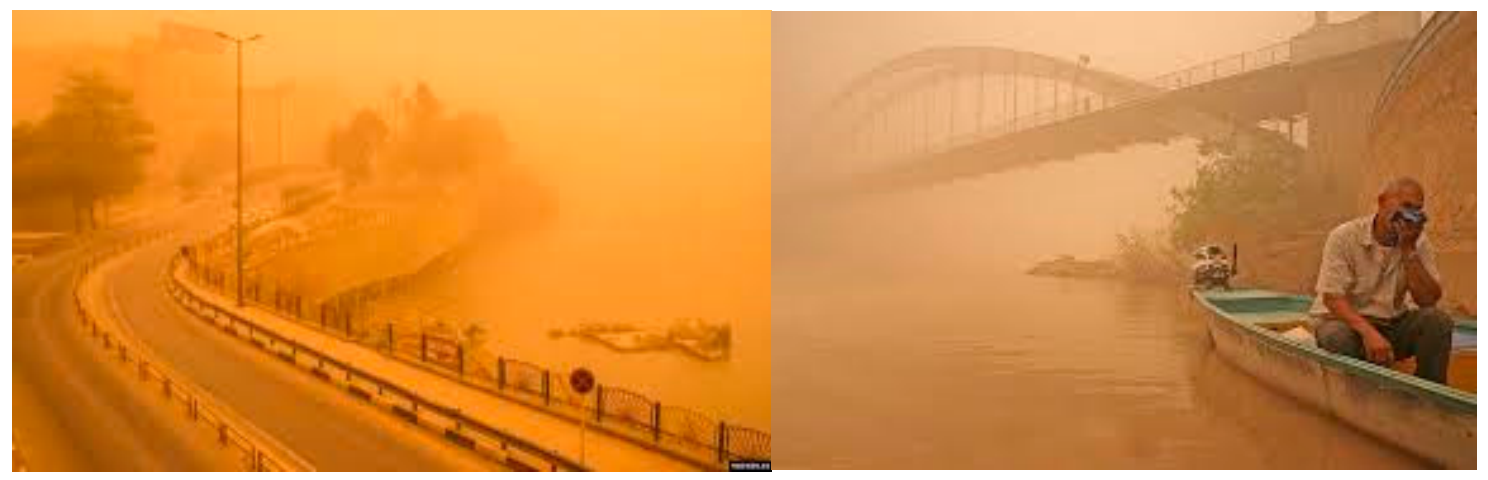

Figure 5. A scene showing dust storm hitting Ahvaz. (Source: http://www.qudsonline.ir/news/505152/; https://www.tasnimnews.com/fa/news/1395/11/26/1328188/). 
The brief description provided in the previous two paragraphs highlighted the major risks that threaten functionality of criticial infrastructure systems in Ahvaz. As the focus of this article is on water, electricty, and gas networks, we briefly explain the characteristics of each in the remainder of this section.

Regarding the water infrastructure, according to the Water and Wastewater Engineering Company, the city's water is mainly sourced from the upstream dam reservoirs with a water provision capacity of about 790,000 $\mathrm{m}^{3}$ (about $60 \%$ from the Karkheh River, about 30\% from the Karun River, and the rest from other sources). There are five water treatment plants across the city, namely, No.1, National Road; No.2, Kianabad; No.3, Golestan; No.4, Ali-Ibn-Mahzyar; and No.5, Karun. The total nominal capacity of these treatment plants is about $500,000 \mathrm{~m}^{3}$ per day. The water infrastructure network serves 369,700 household according to the statistical yearbook of the province [75]. During the 2019 floods, the Ghadir Project for transmission of water from the Karkheh River (proving about $60 \%$ of the total consumed water) went out of service and caused major problems for the residents [17].

Regarding the electricity infrastructure that serves 470,083 households, the city relies on two power plants. The city's electricity is sourced from the Zargan power plant (with a nominal capacity of $418 \mathrm{MWth}$ ( and the Ramin power plant, which is located about $20 \mathrm{~km}$ from the Ahvaz-Masjed Soleiman Road, adjacent to the Karun River. Ramin is the largest thermal power plant in the country, with a nominal capacity of $1850 \mathrm{MWth}[17,76]$. When adverse events such as floods, dust storms, or extreme temperature events (reaching up to about $56^{\circ} \mathrm{C}$ in the middle of summer) occur, the efficiency of these power plants is significantly reduced [77]. This indicates the lack of robustness, redundancy, and flexibility in the infrastructure system of the city, causing difficulties for proper absorption and recovery from disasters.

Very limited data exists on the city's natural gas infrastructure network. Based on the nodal pressure, it can be divided into three major categories, namely, PSI 60, PSI 200, and PSI 400. This infrastructure network serves 155,825 households [17,75]. These high-pressure stations are mostly concentrated in its southwest part of the city, and this concentration increases vulnerability. Besides the issues discussed, critical infrastructure in the city is generally aged and suffers from the lack of proper regular maintenance. Therefore, it is likely to be vulnerable to adverse events.

\subsection{Materials and Methods}

To conduct the spatial analysis, the geo-referenced GIS data related to water, electricity, and gas networks was obtained from the Water and Wastewater Engineering Company, the Grid Management Company, and the National Iranian Gas Company, respectively. To identify indicators and criteria to be used in the spatial analysis of the critical infrastructure resilience, we used a two-round Delphi process to seek expert opinions. While we acknowledge the importance of a wide range of stakeholders in the process, in this preliminary study, only those with expertise related to critical infrastructure networks were involved. Overall, 50 experts took part in the Delphi survey. This is a reasonable number for the Delphi method, because the number of experts does not necessarily need to be high. In fact, there is no strong relationship between the number of experts and the quality of the decisions made [78]. We started the process by inviting a few selected experts to complete the survey. Each expert was also asked to suggest other names to be invited to take part in the survey. All communications, except the first contact with the experts to explain research objectives, which was conducted over Skype, were made through e-mail. The selected experts had expertise in areas related to geography and urban planning, water management, civil engineering, and electrical engineering. They were from both academia and the industry sectors. Some information related to the survey participants is presented in Table 3. The first round was conducted to identify a list of indicators/criteria that could be used for assessing the resilience of critical infrastructure networks and the second round to reach consensus on the list. At the end of the second round, participants were also asked to assign relative weights to the measurement criteria based on a five-point Likert scale, where higher ratings indicate better resilience performance. These weight factors were applied to the GIS-data layers to obtain the 
spatial distribution maps that are presented in the following section (see Figure 6 for the flowchart of the methods).

Table 3. Information related to the survey participants.

\begin{tabular}{cccc}
\hline & Characteristic & N & Percentage \\
\hline \multirow{3}{*}{ Job classification } & Khuzestan Grid Management Company & 12 & $24 \%$ \\
& Ahwaz Urban Water and Wastewater Organization & 9 & $18 \%$ \\
Khuzestan Province Gas Company & 7 & $14 \%$ \\
University professors & 7 & $14 \%$ \\
Education & Bachelor's degree & 15 & $30 \%$ \\
& Master's degree & - & - \\
Gender & PhD & 19 & $38 \%$ \\
& Male & 31 & $62 \%$ \\
Work experience & Female & 16 & $32 \%$ \\
& Less than 5 years & 34 & $68 \%$ \\
& 5 to 7 years & 3 & $06 \%$ \\
& 7 to 9 years & 11 & $22 \%$ \\
Age & More than 9 years & 19 & $38 \%$ \\
& $30-35$ & 17 & $34 \%$ \\
& $36-40$ & 6 & $12 \%$ \\
& $41-45$ & 11 & $22 \%$ \\
& $46-50$ & 13 & $26 \%$ \\
& More than 50 & 11 & $22 \%$ \\
& & 9 & $18 \%$ \\
\hline
\end{tabular}

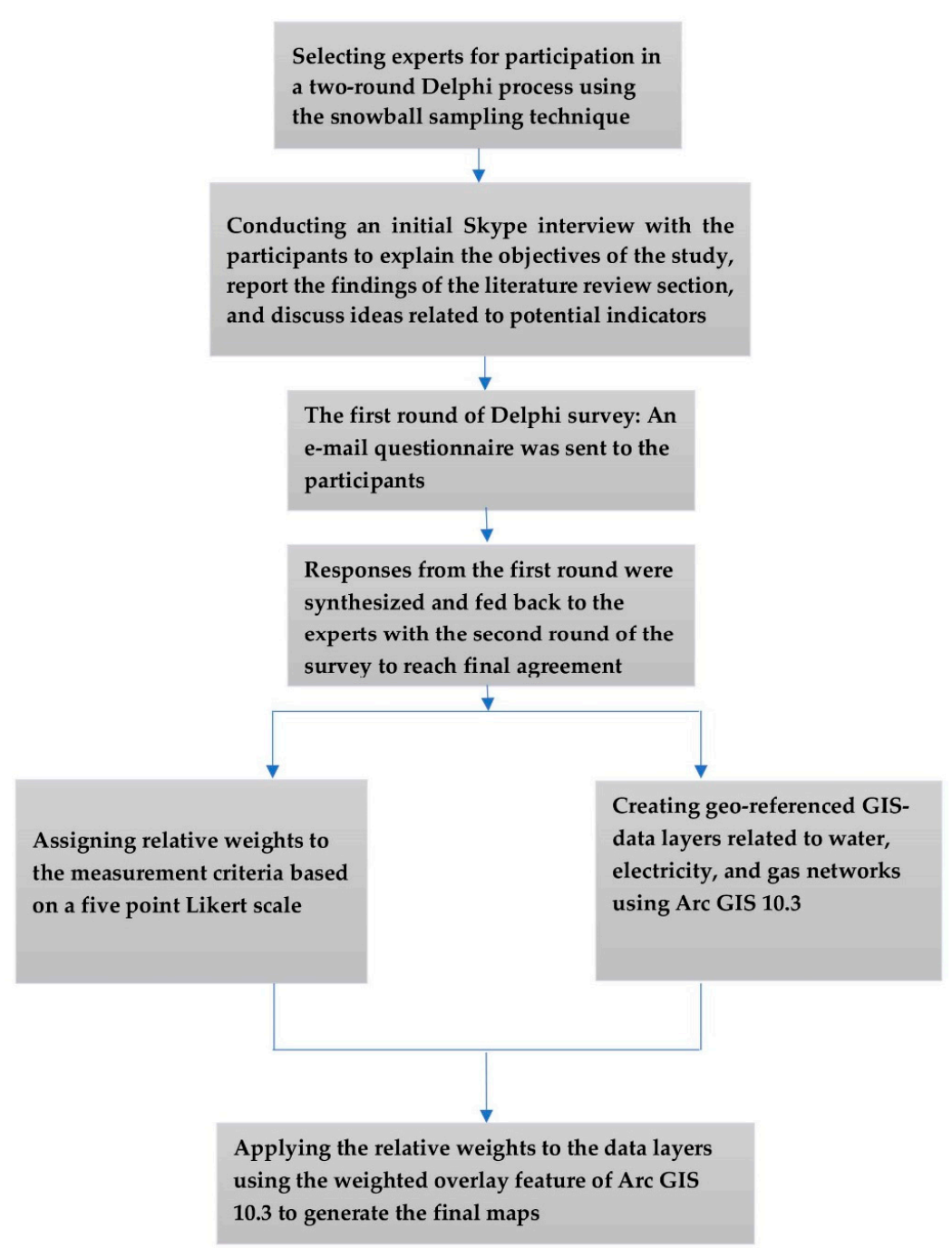

Figure 6. The flowchart of the Delphi and GIS analysis steps. 


\section{Finding and Discussion}

In this section, we first explain the indicators identified using the Delphi process. Following that, we will report the results of the spatial analysis. We will discuss the results in the light of resilience stages and characteristics explained in Section 2.

\subsection{Measurement Criteria}

The measurement criteria were identified based on expert opinions using a two-round Delphi method. The Kendall's W coefficient of concordance (KWC) (Kendall's W) was used for reliability analysis to select the most appropriate measures. This coefficient ranges from 0 (no agreement) to 1 (complete agreement) and can be used to assess the level of agreement between expert opinions $[79,80]$. All criteria listed in Table 4 have coefficients larger than 0.7. Additionally, the relative resilience value of each criterion was determined based on expert opinions and is shown in the third column of Table 4 .

Table 4. Measurement criteria for assessing critical infrastructure resilience.

\begin{tabular}{|c|c|c|c|c|}
\hline Indicators & Measurement Criteria & Resilience Value & KWC in First Round & KWC in Final Round \\
\hline \multirow{5}{*}{$\begin{array}{l}\text { Network physical } \\
\text { texture type }\end{array}$} & Very new (up to 5 years) & 5 & $91 \%$ & $100 \%$ \\
\hline & New (5 to 10 years) & 4 & $89 \%$ & $96 \%$ \\
\hline & Semi-old (10 to 20 years) & 3 & $86 \%$ & $93 \%$ \\
\hline & Old (20 to 30 years) & 2 & $91 \%$ & $100 \%$ \\
\hline & Very old (over 30 years) & 1 & $94 \%$ & $100 \%$ \\
\hline \multirow{5}{*}{ Network Design Pattern } & Dispersed design with high connectivity (Figure 7a) & 5 & $79 \%$ & $97 \%$ \\
\hline & Gridded design (Figure $7 \mathrm{~b}$ ) & 4 & $81 \%$ & $98 \%$ \\
\hline & Semi-gridded design (Figure 7c) & 3 & $75 \%$ & $91 \%$ \\
\hline & Radial design (Figure 7d) & 2 & $79 \%$ & $94 \%$ \\
\hline & Organic and irregular design (Figure 7e) & 1 & $87 \%$ & $96 \%$ \\
\hline \multirow{5}{*}{$\begin{array}{c}\text { Scale of service } \\
\text { provision (population) }\end{array}$} & Up to 10,000 & 5 & $88 \%$ & $97 \%$ \\
\hline & $10,001-25,000$ & 4 & $83 \%$ & $97 \%$ \\
\hline & $25,001-50,000$ & 3 & $91 \%$ & $100 \%$ \\
\hline & $50,001-75,000$ & 2 & $91 \%$ & $100 \%$ \\
\hline & More than 75,001 & 1 & $89 \%$ & $98 \%$ \\
\hline
\end{tabular}

Note: 5 is very high resilience, 4 is high resilience, 3 is medium resilience, 2 is poor resilience, and 1 is very poor resilience. KWC: Kendall's W coefficient. The values were assigned considering the resilience stages and characteristics mentioned in Table 1.

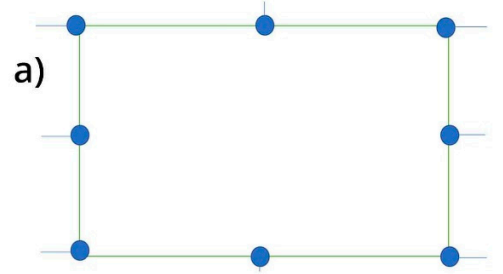

b)

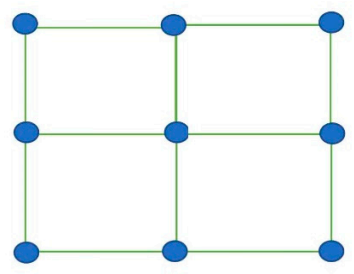

c)
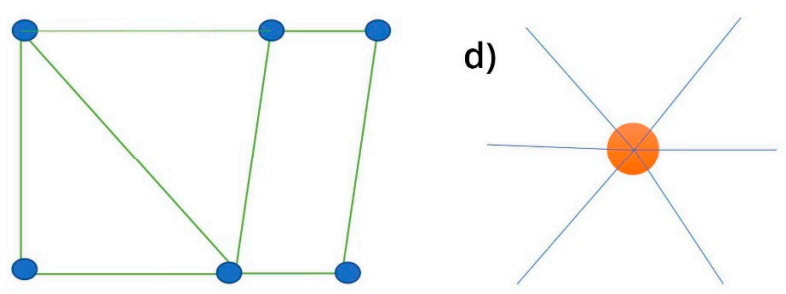

e)

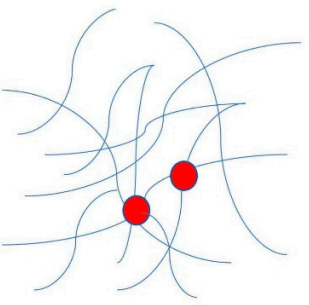

Figure 7. Different types of network design. (a) Dispersed design with high connectivity, (b) Gridded design, (c) Semi-gridded design, (d) Radial design, (e) Organic and irregular design. 
The first set of criteria are related to the type of network physical texture. These are related to preparedness and robustness characteristics of resilience. There was a high consensus among the experts that infrastructure age is important as it is a good indicator of the abilities to resist and absorb shocks. The measurement criteria related to this indicator can range from very new to very old. Newer textures feature higher levels of robustness and are, therefore, expected to be better capable of absorbing shocks and maintaining the functionality of the critical infrastructure. Recovery is also assumed to be easier in newer textures because the extent of damage is likely to be lower and the road network is also more suitable for emergency access and evacuation.

Regarding the network design patterns that are more related to redundancy and flexibility characteristics, five different types of network design were identified as shown in Figure 7. Based on expert opinions, radial design patterns are common in Ahvaz. Such centralized patterns feature high dependence on a limited number of central nodes, which, if disrupted, result in major functionality loss across the city. In contrast, design patterns that are decentralized and feature robust and redundant nodes are more flexible and adaptable because disruption in one node does not result in total functionality disruption in the system (Figure $7 \mathrm{a}-\mathrm{c}$ ). This facilitates better absorption and recovery capacities. In contrast, radial and irregular patterns are less resilient (Figure $7 \mathrm{~d}, \mathrm{e}$ ) due to limited redundancy and high reliance on a limited number of nodes. Under such configurations, disruptions in one node will render the whole network vulnerable [30].

As for the scale of service provision that is related to preparedness and robustness characteristics, according to the experts, larger scales are less desirable as any potential losses in functionality will affect a larger number of populations. Additionally, larger scales may result in higher demand during peak hours, thereby increasing the pressure on the network. Accordingly, a smaller scale of service provision is more desirable in terms of preparation, absorption, and recovery capacities.

\subsection{Spatial Analysis of Critical Infrastructure Resilience}

Using the measurement criteria explained in the previous section, we conducted a spatial analysis of water, gas, and electricity infrastructure networks in Ahvaz. We will discuss the results in the context of the eight municipality regions of the city that are shown in Figure 8.

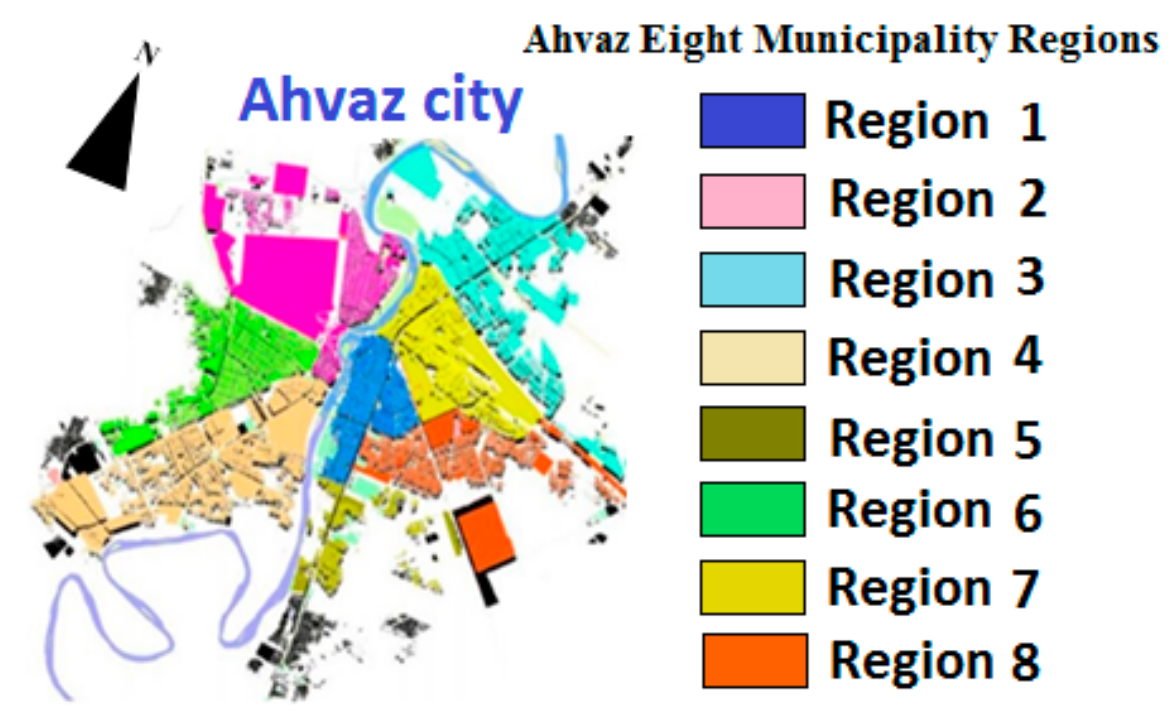

Figure 8. Municipality regions of Ahvaz.

4.2.1. Water

The spatial resilience analysis is conducted based on the three indicator sets mentioned in the previous section, namely, network physical texture type, network design pattern, and scale of service 
provision (Figure 9). We first examined the network physical texture based on the age of the water network. Obviously, based on criteria listed on Table 4, older textures are less resilient.
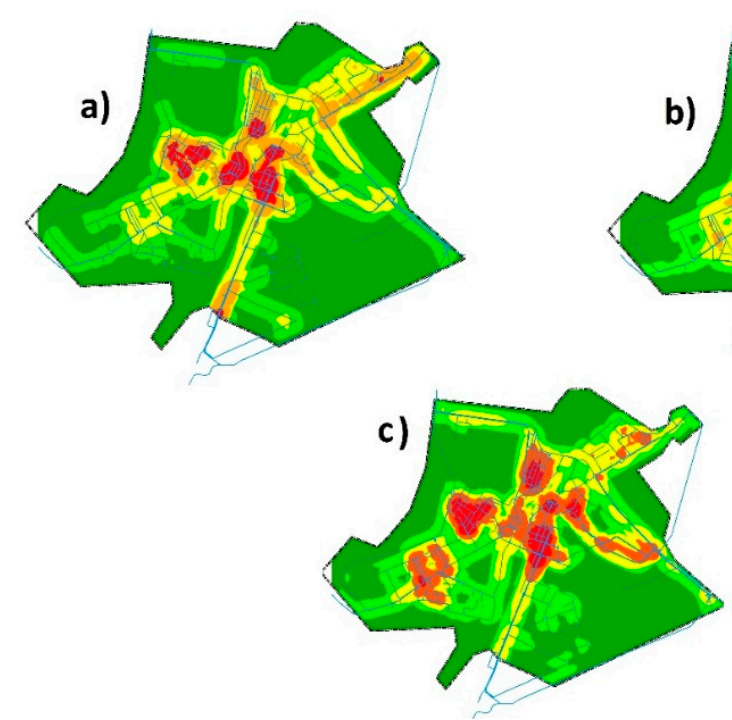

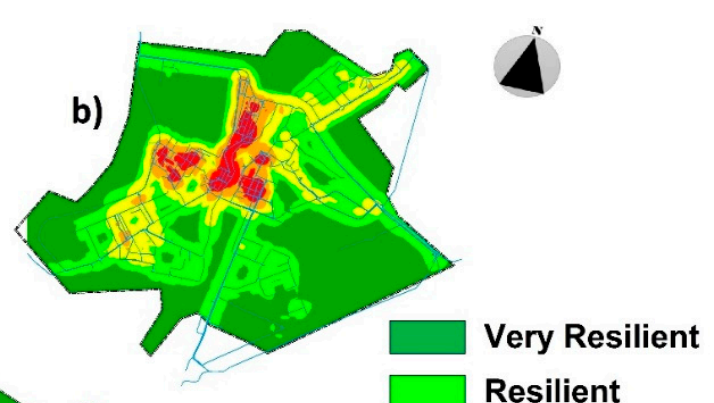

Resilient

Semi - Resilient

Low Resilience

Very Low Resilience

Figure 9. Spatial distribution of the resilience of water infrastructure based on (a) urban fabric type, (b) network design pattern criteria, and c) scale of service provision.

As shown in Figure 9, and based on urban fabric type (a), the central parts of the city that are mainly located in Region 1, as well as the northern parts of Region No.6, show poor performance due to their aged water infrastructure. These are old and poor neighborhoods such as Ameri, Shilang Abad, Amanieh, and Kamplo. It can be seen from Figure 9 that water infrastructure resilience increases with distance from the city center. This is not surprising since the infrastructure in those areas is less old.

In terms of the network design pattern, and as shown in Table 4, decentralized patterns with multiple robust nodes are assigned higher values of resilience. Figure $9 b$ shows the spatial resilience of the water network based on these criteria. According to Figure 9b, the water infrastructure network performs poorly in the central parts of Region No.1 (Ameri, Abdolhamid baazar and Padadshahr neighborhoods), the northern parts of Region 6 (Salimabad, Ahanafshar, and Kamplo neighborhoods) and the southern and central part of Region No.2 (Amanieh, Kianpars \& Seyedkhalaf neighborhoods). The design pattern of the water network infrastructure in these neighborhoods is centralized and irregular. As a result, they lack adequate levels of flexibility and adaptability and are susceptible to significant functionality loss at the time of disaster.

Regarding the third indicator set (scale of service provision), it was discussed that smaller scales are more desirable. This is because, in case of major disruptions, smaller numbers of people will be affected. The red parts in Figure $9 \mathrm{c}$ are those areas of the city where the water network provides service to large numbers of population $(>75,000)$. These are areas located in highly populated regions (i.e., Regions No.1, 3, 4, and 6). Additionally, Regions No.1 (e.g., Bazzar Abdolhamid), No.2 (e.g., Amanieh and Kianpars), 4 (Golestan), and No.6 (Kamplo) host many commercial and industrial activities that further increase their demand for water. To enhance resilience, adequate preparedness measures should be taken to increase robustness and redundancy of the network in these areas.

\subsubsection{Electricity}

We followed similar procedures to examine spatial resilience of the electricity network infrastructure. Results related to the network physical texture type, network design pattern, and scale of service provision are reported in Figure 10. 


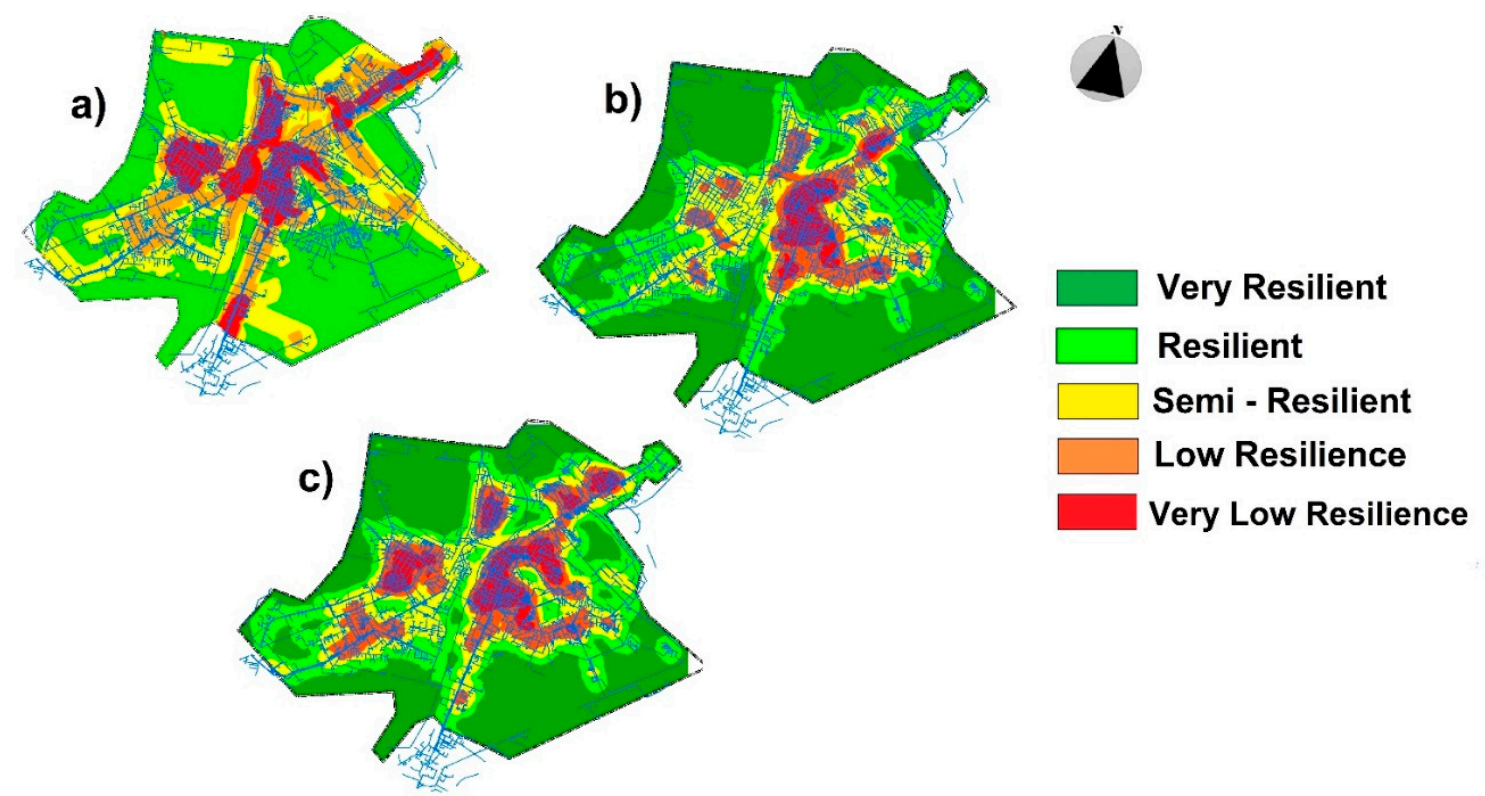

Figure 10. Spatial distribution of the resilience of electricity infrastructure based on network physical texture type (a), network design pattern (b), and scale of service provision (c).

Regarding the network physical texture criteria, Figure 10a shows that central parts of the city (Region No.1, which exactly matches the Padad, Akhar asphalt, Bagh Moein and Kuy Dovlat neighborhoods) as well as the northern parts of Region No.6 (i.e., north and south Kamplo, Shilangabad, Salimabad and Kian neighborhoods), the southern parts of Region No.4 (Golestan and Fardis) and 5 (Kootabdolah, It is worth noting that this region has recently been separated from the city and is now known as the city of Karun ), and, finally, the central parts of Region No.3 (Zeytoon and Kourosh neighborhoods) have low levels of resilience. It can be seen that these areas are located along the Karun River and are, therefore, exposed to potentially severe floods. The old electricity infrastructure in these regions increases vulnerability to flood risk as well as other risks such as extreme heat and dust storms.

Results for the network design pattern criteria are to some extent different from the previous results. As Figure 10b shows, here the eastern parts of the city are less resilient. This is due to the dominance of radial and irregular patterns in these areas (Regions No.1, which is the old and central part of the city, No. 7 (the Hasir Abad, Kuy Ramazan, Manba Ab and Sepidar neighborhoods) and No. 3 (Zeytoon)). These radial and irregular patterns lack appropriate levels of redundancy and flexibility.

As for the scale of service provision, Figure 10c shows that there is higher energy demand in the central (Region No.1) and eastern parts (Region No.7 and the southern part of Region No.8 (such as the Kuy Tolab, Janbazan and Padad 1 neighborhoods)) of the city. In addition, high levels of energy demand can also be observed in some western parts (i.e., the northern part of Region No.6 and the southern and central parts of Region No.2 (especially the Amanieh and Kianpars neighborhoods), and also the southern part of Region 4). In addition to being highly populated, these areas include some major city slums like Hasirabad, Shilangabad, Lashkarabad and Ameri, where the network infrastructure is aged and poorly maintained. Therefore, to increase resilience, the robustness, redundancy, and flexibility of the network in these areas should be improved.

\subsubsection{Gas}

Doing the same analyses for the city gas network, the areas that need to be improved were identified. Regarding the network physical texture type that is related to the age of network infrastructure, Figure 11a shows that these areas perform poorly due to their old infrastructure: the central part of the city (Region No.1), Region No.6 and the southern part of Region No.4. They are, 
therefore, susceptible to serious issues linked to the vulnerability of the old city gas distribution network (e.g., possible explosions).
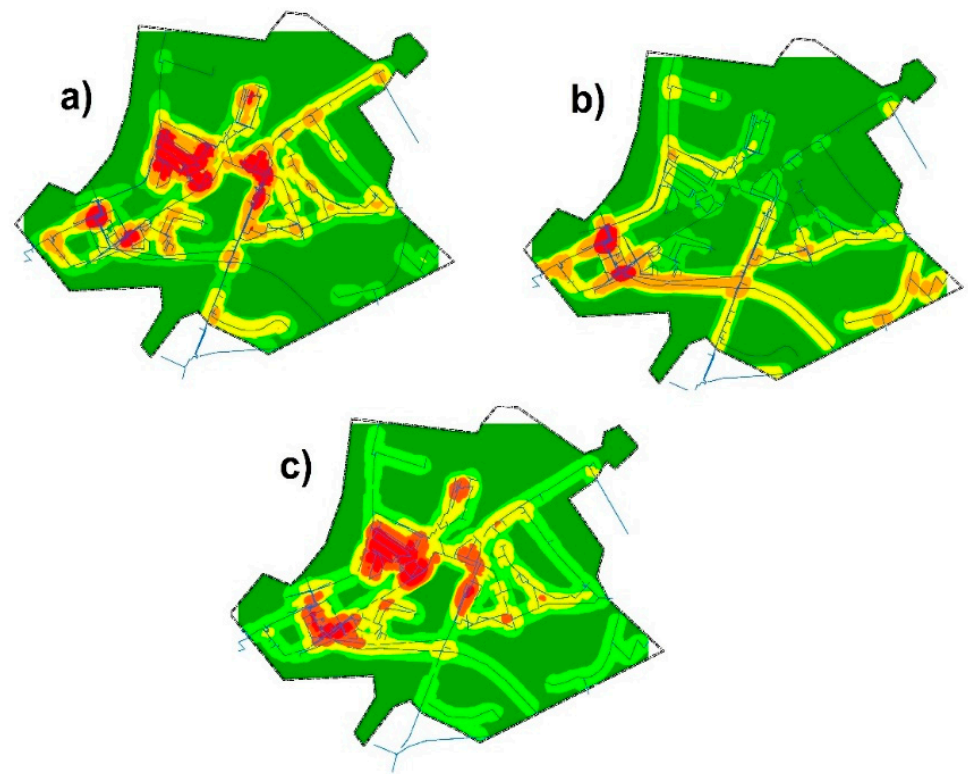

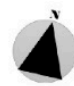

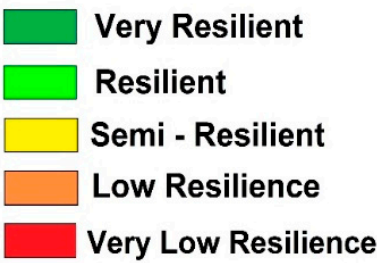

Figure 11. Spatial distribution of the resilience of electricity infrastructure based on network physical texture type (a), network design pattern (b), and scale of service provision (c).

The network design pattern indicator showed that the main natural gas pressure regulator stations and the main distribution pipelines in southern part of Regions No.4 and 6 have radial and irregular design patterns. Therefore, they do not perform well in terms of resilience characteristics such as redundancy and flexibility. Finally, analysis based on the scale of service provision shows that demand is higher in Region No.6, central parts of Region No.1, central and northern parts of Region No.2, and southern parts of Region No.4 (Figure 11c). As shown in the previous analysis, some of these areas lack new, redundant, and flexible infrastructure networks. Any disruptions in these areas are, therefore, likely to cause significant socio-economic damages to the city and its citizens.

\section{Conclusions}

Critical infrastructures are essential constituent elements of cities that play important roles in maintaining the socio-economic prosperity of the citizens. Accordingly, many scholars have emphasized the importance of taking necessary measures to ensure reliability and continuous functionality of the critical infrastructure by enhancing resilience characteristics such as robustness, redundancy, and flexibility $[51,81-83]$. The issue of critical infrastructure resilience has gained growing importance in recent years given the projections about increase in the frequency and intensity of disastrous events. Consequently, a paradigm shift in emphasis from infrastructure protection to infrastructure resilience has been observed in the past few years [4]. Despite this, there is still limited research exploring the resilience of critical infrastructure networks. This study, therefore, should be regarded as a preliminary step toward filling this gap. In this study, we used criteria related to the physical texture, design pattern, and scale of service provision to spatially map the resilience of water, electricity, and city gas networks in Ahvaz, an Iranian city that has faced several major adverse events during the past few years. The selected measurement criteria are used to understand the city's performance against characteristics such as preparedness, robustness, redundancy, and flexibility, which are argued to be critical for improving critical infrastructure resilience $[12,48,68]$. These characteristics influence the system's capacity to absorb shocks and rapidly return to normal conditions $[12,48,81]$. 
As mentioned in the Introduction, the main purpose of this study was to conduct a spatial analysis of the resilience of critical infrastructure networks to identify areas that need to be prioritized for further improvement. Figure 12 shows the overall resilience of the critical infrastructure networks (water, electricity and gas) in Ahvaz. Based on the results, we have identified four vulnerability hotspots. Point A in Figure 12 refers to the central area of the city, which is also the historical core of the city and is characterized by its high population density, old infrastructure, and irregular physical patterns. Accordingly, this area performs poorly against all three sets of criteria (related to water, electricity, and gas networks) discussed in this study. Point B is located in the central part of Region No.3, where informal settlements and old public housing units are dominant types of development. This area is also characterized by old infrastructure, high population density, and irregular urban patterns. At both points A and B, improving robustness, redundancy, and flexibility of the critical infrastructure network should be prioritized.

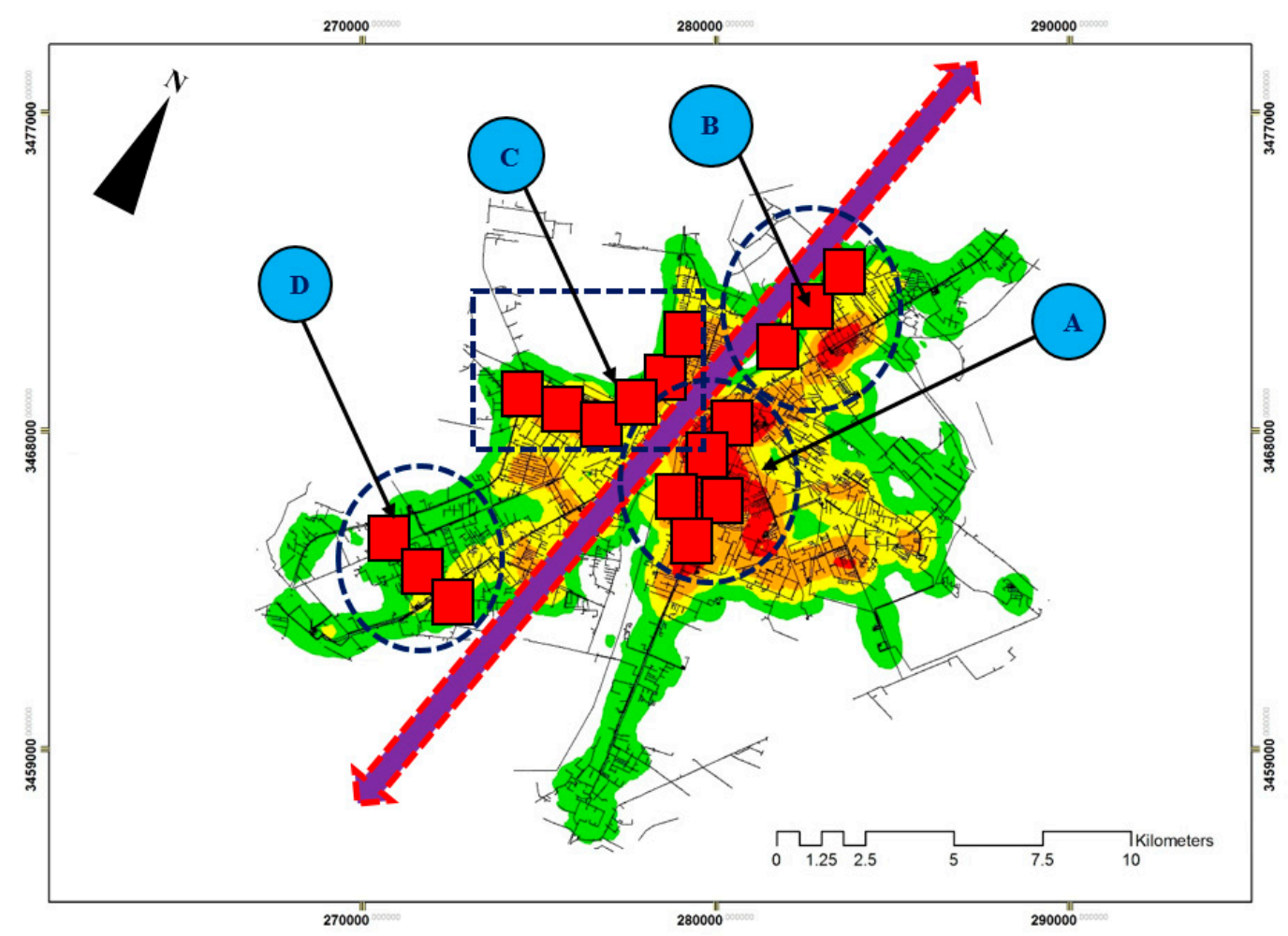

Figure 12. Spatial resilience of critical infrastructure in Ahvaz.

Point C, which is shown using an L-shaped form in Figure 12, overlaps with the central part of Region No.2 and the northern part of Region No.6. While, unlike at the previous two points, the infrastructure is not old, this area also needs redundancy and flexibility improvements since it has the highest population density (high demand), and the centralized infrastructure networks follow radial patterns that are vulnerable to adverse events. Similar conditions can be observed at Point D, which is located in southern part of Regions No.4 and 6, where major industrial and educational establishments, and main network distribution control stations are located. Resilience characteristics in these hotspots should be enhanced in order to improve the absorption and recovery capacities of the city in the face of adverse events.

Overall, this study finds that limitations in terms of robustness and redundancy are major issues that undermine the resilience of critical infrastructure networks in Ahvaz. Efforts should therefore be taken to address these issues. However, it should be noted that enhancing robustness, redundancy, and flexibility in existing cities would be very challenging as it requires significant efforts and resources. This is particularly challenging in developing contexts such as Iran, which are facing challenges in 
sustaining investment for urban renewal and urban development plans. Exploring opportunities for financing renewal and redevelopment initiatives should therefore be prioritized in the future research. In the meantime, it is necessary to develop strategies for controlling and regulating urban development in the city to avoid additional lock-in effects in the future. This could, for instance, be through efforts to ensure compliance with the city's master plan and the building codes.

Another major issue that needs to be noted is that resilience has multiple dimensions and this study has only focused on the physical dimension. In fact, other socio-economic and institutional dimensions need to be appropriately explored in the future to understand how they can contribute to dealing with the issues highlighted in this paper. Emphasis on these dimensions is particularly important in the historical parts of the city. At the end, it should also be acknowledged that this study has relied on the expertise of a limited number of stakeholders. Future research should consider involving a wider range of stakeholders in the process. In fact, involving more stakeholders may also lead to identification of a larger number of indicators in the process. It may also result in some changes in the weights assigned, given that weighting relies on the participants' judgements. Despite these limitations, we hope that this study can inform urban policy makers of the areas that need to be prioritized in order to improve critical infrastructure resilience in Ahvaz.

Author Contributions: Conceptualization, H.A. and A.S.; methodology, H.A.; formal analysis, H.A.; data curation, H.A.; writing —original draft preparation, A.S. and H.A.; writing—review and editing, A.S. and H.A.; visualization, H.A.; supervision, A.S. All authors have read and agreed to the published version of the manuscript.

Funding: This research received no external funding.

Conflicts of Interest: The authors declare no conflict of interest.

\section{References}

1. Sharifi, A. Urban form resilience: A meso-scale analysis. Cities 2019, 93, 238-252. [CrossRef]

2. Sharifi, A. A critical review of selected tools for assessing community resilience. Ecol. Indic. 2016, 69, 629-647. [CrossRef]

3. Ribeiro, P.J.G.; Gonçalves, L. Urban resilience: A conceptual framework. Sustain. Cities Soc. 2019, 50, 101625. [CrossRef]

4. Pursiainen, C. Critical infrastructure resilience: A Nordic model in the making? Int. J. Disaster Risk Reduct. 2018, 27, 632-641. [CrossRef]

5. Ouyang, M.; Liu, C.; Xu, M. Value of resilience-based solutions on critical infrastructure protection: Comparing with robustness-based solutions. Reliab. Eng. Syst. Saf. 2019, 190, 106506. [CrossRef]

6. Cedergren, A.; Johansson, J.; Hassel, H. Challenges to critical infrastructure resilience in an institutionally fragmented setting. Saf. Sci. 2018, 110, 51-58. [CrossRef]

7. McDaniels, T.; Chang, S.; Cole, D.; Mikawoz, J.; Longstaff, H. Fostering resilience to extreme events within infrastructure systems: Characterizing decision contexts for mitigation and adaptation. Glob. Environ. Chang. 2008, 18, 310-318. [CrossRef]

8. Labaka, L.; Hernantes, J.; Sarriegi, J.M. A holistic framework for building critical infrastructure resilience. Technol. Soc. 2016, 103, 21-33. [CrossRef]

9. Setola, R.; Luiijf, E.; Theocharidou, M. Critical Infrastructures, Protection and Resilience. In Managing the Complexity of Critical Infrastructures: A Modelling and Simulation Approach; Setola, R., Rosato, V., Kyriakides, E., Rome, E., Eds.; Springer International Publishing: Cham, Switzerland, 2016; pp. 1-18.

10. UNISDR (United Nations Office for Disaster Risk Reduction). Disaster risk and resilience. In Thematic Think Piece, UN System Task Force on the Post-2015 UN Development Agenda; United Nation: Geneva, Switzerland, 2012.

11. Mao, Q.; Li, N.; Peña-Mora, F. Quality function deployment-based framework for improving the resilience of critical infrastructure systems. Int. J. Crit. Infrastruct. Prot. 2019, 26, 100304. [CrossRef]

12. Rehak, D.; Senovsky, P.; Hromada, M.; Lovecek, T. Complex approach to assessing resilience of critical infrastructure elements. Int. J. Crit. Infrastruct. Prot. 2019, 25, 125-138. [CrossRef]

13. Sharifi, A.; Chelleri, L.; Fox-Lent, C.; Grafakos, S.; Pathak, M.; Olazabal, M.; Moloney, S.; Yumagulova, L.; Yamagata, Y. Conceptualizing Dimensions and Characteristics of Urban Resilience: Insights from a Co-Design Process. Sustainability 2017, 9, 1032. [CrossRef] 
14. Hickford, A.J.; Blainey, S.P.; Ortega Hortelano, A.; Pant, R. Resilience engineering: Theory and practice in interdependent infrastructure systems. Environ. Syst. Decis. 2018, 38, 278-291. [CrossRef]

15. Pourghasemi, H.R.; Gayen, A.; Panahi, M.; Rezaie, F.; Blaschke, T. Multi-hazard probability assessment and mapping in Iran. Sci. Total Environ. 2019, 692, 556-571. [CrossRef] [PubMed]

16. Jahangir, M.H.; Mousavi Reineh, S.M.; Abolghasemi, M. Spatial predication of flood zonation mapping in Kan River Basin, Iran, using artificial neural network algorithm. Weather Clim. Extrem. 2019, $25,100215$. [CrossRef]

17. Alizadeh, H. The Assessment of Critical Infrastructure Resilience in View of Passive Defense a Case Study of Ahvaz Metropolis, Iran Passive Defense Organization; Iran Passive Defense Organization: Tehran, Iran, 2019.

18. Romero-Lankao, P.; Gnatz, D.M.; Wilhelmi, O.; Hayden, M. Urban Sustainability and Resilience: From Theory to Practice. Sustainability 2016, 8, 1224. [CrossRef]

19. Zhang, X.; Li, H. Urban resilience and urban sustainability: What we know and what do not know? Cities 2018, 72, 141-148. [CrossRef]

20. Provan, D.J.; Woods, D.D.; Dekker, S.W.A.; Rae, A.J. Safety II professionals: How resilience engineering can transform safety practice. Reliab. Eng. Syst. Saf. 2020, 195, 106740. [CrossRef]

21. Oliva, S.; Lazzeretti, L. Measuring the economic resilience of natural disasters: An analysis of major earthquakes in Japan. CityCult. Soc. 2018, 15, 53-59. [CrossRef]

22. Pashapour, S.; Bozorgi-Amiri, A.; Azadeh, A.; Ghaderi, S.F.; Keramati, A. Performance optimization of organizations considering economic resilience factors under uncertainty: A case study of a petrochemical plant. J. Clean. Prod. 2019, 231, 1526-1541. [CrossRef]

23. Brown, R. Building children and young people's resilience: Lessons from psychology. Int. J. Disaster Risk Reduct. 2015, 14, 115-124. [CrossRef]

24. Holling, C.S. Resilience and Stability of Ecological Systems. Annu. Rev. Ecol. Syst. 1973, 4, 1-23. [CrossRef]

25. Gaillard, J.C. Vulnerability, capacity and resilience: Perspectives for climate and development policy. J. Int. Dev. 2010, 22, 218-232. [CrossRef]

26. Blockley, D.; Agarwal, J.; Godfrey, P. Infrastructure resilience for high-impact low-chance risks. Proc. Inst. Civ. Eng.-Civ. Eng. 2012, 165, 13-19. [CrossRef]

27. Wan, C.; Yang, Z.; Zhang, D.; Yan, X.; Fan, S. Resilience in transportation systems: A systematic review and future directions. Transp. Rev. 2018, 38, 479-498. [CrossRef]

28. Sharifi, A.; Yamagata, Y. Resilience-Oriented Urban Planning. In Resilience-Oriented Urban Planning: Theoretical and Empirical Insights; Yamagata, Y., Sharifi, A., Eds.; Springer International Publishing: Cham, Switzerland, 2018; pp. 3-27.

29. Ko, Y.; Barrett, B.F.D.; Copping, A.E.; Sharifi, A.; Yarime, M.; Wang, X. Energy Transitions Towards Low Carbon Resilience: Evaluation of Disaster-Triggered Local and Regional Cases. Sustainability 2019, 11, 6801. [CrossRef]

30. Sharifi, A.; Yamagata, Y. Principles and criteria for assessing urban energy resilience: A literature review. Renew. Sustain. Energy Rev. 2016, 60, 1654-1677. [CrossRef]

31. TNA. Disaster Resilience: A National Imperative; National Academies Press: Washington, DC, USA, 2012.

32. Kapucu, N.; Hawkins, C.V.; Rivera, F.I. Disaster Preparedness and Resilience for Rural Communities. Risk Hazards Crisis Public Policy 2013, 4, 215-233. [CrossRef]

33. Berle, Ø.; Norstad, I.; Asbjørnslett Bjorn, E. Optimization, risk assessment and resilience in LNG transportation systems. Supply Chain Manag. Int. J. 2013, 18, 253-264. [CrossRef]

34. Faturechi, R.; Miller-Hooks, E. Measuring the Performance of Transportation Infrastructure Systems in Disasters: A Comprehensive Review. J. Infrastruct. Syst. 2015, 21, 04014025. [CrossRef]

35. Maiwald, M. Robust Evacuation Planning for Urban Areas; Springer International Publishing: Cham, Switzerland, 2019; pp. 23-28.

36. Haimes, Y.Y. On the Definition of Resilience in Systems. Risk Anal. 2009, 29, 498-501. [CrossRef]

37. Reggiani, A. Network resilience for transport security: Some methodological considerations. Transp. Policy 2013, 28, 63-68. [CrossRef]

38. Adams, T.M.; Bekkem, K.R.; Toledo-Durán, E.J. Freight Resilience Measures. J. Transp. Eng. 2012, 138, 1403-1409. [CrossRef]

39. Cox, A.; Prager, F.; Rose, A. Transportation security and the role of resilience: A foundation for operational metrics. Transp. Policy 2011, 18, 307-317. [CrossRef] 
40. Blackman, D.; Nakanishi, H.; Benson, A.M. Disaster resilience as a complex problem: Why linearity is not applicable for long-term recovery. Technol. Soc. 2017, 121, 89-98. [CrossRef]

41. Rehak, D.; Senovsky, P.; Slivkova, S. Resilience of Critical Infrastructure Elements and Its Main Factors. Systems 2018, 6, 21. [CrossRef]

42. Tschakert, P.; Dietrich, K.A. Anticipatory Learning for Climate Change Adaptation and Resilience. Ecol. Soc. 2010, 15, 11. [CrossRef]

43. Nelson, D.R.; Adger, W.N.; Brown, K. Adaptation to Environmental Change: Contributions of a Resilience Framework. Annu. Rev. Environ. Resour. 2007, 32, 395-419. [CrossRef]

44. Ng, S.T.; Xu, F.J.; Yang, Y.; Lu, M.; Li, J. Necessities and challenges to strengthen the regional infrastructure resilience within city clusters. Procedia Eng. 2018, 212, 198-205. [CrossRef]

45. Govindarajulu, D. Strengthening institutional and financial mechanisms for building urban resilience in India. Int. J. Disaster Risk Reduct. 2020, 47, 101549. [CrossRef]

46. Yang, Y.; Ng, S.T.; Zhou, S.; Xu, F.J.; Li, H. A physics-based framework for analyzing the resilience of interdependent civil infrastructure systems: A climatic extreme event case in Hong Kong. Sustain. Cities Soc. 2019, 47, 101485. [CrossRef]

47. Nazarnia, H.; Sarmasti, H.; Olivia Wills, W. Application of household disruption data to delineate critical infrastructure resilience characteristics in the aftermath of disaster: A case study of Bhaktapur, Nepal. Saf. Sci. 2020, 121, 573-579. [CrossRef]

48. Liu, W.; Song, Z. Review of studies on the resilience of urban critical infrastructure networks. Reliab. Eng. Syst. Saf. 2020, 193, 106617. [CrossRef]

49. Bobylev, N.; Hunt, D.V.; Jefferson, I.; Rogers, C.D. Sustainable infrastructure for resilient urban environments. Adv. Undergr. Space Dev. 2013, 906-917.

50. Guidotti, R.; Chmielewski, H.; Unnikrishnan, V.; Gardoni, P.; McAllister, T.; van de Lindt, J. Modeling the resilience of critical infrastructure: the role of network dependencies. Sustain. Resilient Infrastruct. 2016, 1, 153-168. [CrossRef]

51. Yusta, J.M.; Correa, G.J.; Lacal-Arántegui, R. Methodologies and applications for critical infrastructure protection: State-of-the-art. Energy Policy 2011, 39, 6100-6119. [CrossRef]

52. Directive, C. 114/EC of 8 December 2008 on the identification and designation of European critical infrastructures and the assessment of the need to improve their protection. Off. J. Eur. Union L 2008, $345,75-82$.

53. Security, U.D.O.H. National Infrastructure Protection Plan 2009; United States Department of Homeland Security: Washington, DC, USA, 2009.

54. Ouyang, M.; Duenas-Osorio, L.; Min, X. A three-stage resilience analysis framework for urban infrastructure systems. Struct. Saf. 2012, 36-37, 23-31. [CrossRef]

55. Petit, F.; Bassett, G.; Black, R.; Buehring, W.; Collins, M.; Dickinson, D.; Fisher, R.; Haffenden, R.; Huttenga, A.; Klett, M. Resilience Measurement Index: An Indicator of Critical Infrastructure Resilience; Argonne National Lab.(ANL): Argonne, IL, USA, 2013.

56. Shin, S.; Lee, S.; Judi, D.R.; Parvania, M.; Goharian, E.; McPherson, T.; Burian, S.J. A Systematic Review of Quantitative Resilience Measures for Water Infrastructure Systems. Water 2018, 10, 164. [CrossRef]

57. Cimellaro, G.; Tinebra, A.; Renschler, C.; Fragiadakis, M. New resilience index for urban water distribution networks. J. Struct. Eng. 2016, 142, C4015014. [CrossRef]

58. Herrera, M.; Abraham, E.; Stoianov, I. A Graph-Theoretic Framework for Assessing the Resilience of Sectorised Water Distribution Networks. Water Resour. Manag. 2016, 30, 1685-1699. [CrossRef]

59. Yazdani, A.; Otoo, R.A.; Jeffrey, P. Resilience enhancing expansion strategies for water distribution systems: A network theory approach. Environ. Model. Softw. 2011, 26, 1574-1582. [CrossRef]

60. Chang, S.E.; Shinozuka, M. Measuring improvements in the disaster resilience of communities. Earthq. Spectra 2004, 20, 739-755. [CrossRef]

61. Balaei, B.; Wilkinson, S.; Potangaroa, R.; McFarlane, P. Investigating the technical dimension of water supply resilience to disasters. Sustain. Cities Soc. 2020, 56, 102077. [CrossRef]

62. Golara, A.; Esmaeily, A. Quantification and enhancement of the resilience of infrastructure networks. J. Pipeline Syst. Eng. Pract. 2017, 8, 04016013. [CrossRef] 
63. Gasser, P.; Lustenberger, P.; Cinelli, M.; Kim, W.; Spada, M.; Burgherr, P.; Hirschberg, S.; Stojadinovic, B.; Sun, T.Y. A review on resilience assessment of energy systems. Sustain. Resilient Infrastruct. 2019, 1-27. [CrossRef]

64. Heinimann, H.R.; Hatfield, K. Infrastructure resilience assessment, management and governance-state and perspectives. In Resilience and Risk; Springer: Berlin/Heidelberg, Germany, 2017; pp. 147-187.

65. Carvalho, R.; Buzna, L.; Bono, F.; Masera, M.; Arrowsmith, D.K.; Helbing, D. Resilience of natural gas networks during conflicts, crises and disruptions. PLoS ONE 2014, 9, e90265. [CrossRef]

66. Francis, R.; Bekera, B. A metric and frameworks for resilience analysis of engineered and infrastructure systems. Reliab. Eng. Syst. Saf. 2014, 121, 90-103. [CrossRef]

67. MacKenzie, C.A.; Zobel, C.W. Allocating resources to enhance resilience, with application to superstorm sandy and an electric utility. Risk Anal. 2016, 36, 847-862. [CrossRef]

68. Ouyang, M.; Dueñas-Osorio, L. Multi-dimensional hurricane resilience assessment of electric power systems. Struct. Saf. 2014, 48, 15-24. [CrossRef]

69. Panteli, M.; Mancarella, P.; Trakas, D.N.; Kyriakides, E.; Hatziargyriou, N.D. Metrics and quantification of operational and infrastructure resilience in power systems. IEEE Trans. Power Syst. 2017, 32, 4732-4742. [CrossRef]

70. Guttromson, R.; Watson, J.P. Defining, Measuring, and Improving Resilience of Electric Power Systems. Smart Grid Handb. 2016, 1-21. [CrossRef]

71. Farsani, M.H.; Shirmardi, M.; Alavi, N.; Maleki, H.; Sorooshian, A.; Babaei, A.; Asgharnia, H.; Marzouni, M.B.; Goudarzi, G. Evaluation of the relationship between PM10 concentrations and heavy metals during normal and dusty days in Ahvaz, Iran. Aeolian Res. 2018, 33, 12-22. [CrossRef]

72. Ahvaz. Statistical Yearbook of Ahvaz Municipality Areas, Ahvaz Municipality; Ahvaz Municipality: Ahvaz, Iran, 2019.

73. Salehi-Vaziri, M.; Salmanzadeh, S.; Baniasadi, V.; Jalali, T.; Mohammadi, T.; Azad-Manjiri, S.; Jamshidi, Y.; Khakifirouz, S.; Fazlalipour, M. An Outbreak of Crimean-Congo Hemorrhagic Fever in the South West of Iran. Jundishapur J. Microbiol. 2017, 10, e60196. [CrossRef]

74. TravelPersia about Persia/Iran's Provinces Khuzestan. Available online: https://www.persiaadvisor.travel/ about-persia/khuzestan-province/ (accessed on 15 February 2020).

75. KSY. Khuzestan Statistical Yearbook, Khuzestan Province; Khuzestan Province: Ahvaz, Iran, 2016.

76. KWPO. Handbook of State of Energy Resources and Production in Khuzestan Province, Khuzestan Water and Power Organization; Khuzestan Water and Power Organization: Ahvaz, Iran, 2018.

77. Keikhosravi, Q. The effect of heat waves on the intensification of the heat island of Iran's metropolises (Tehran, Mashhad, Tabriz, Ahvaz). Urban Clim. 2019, 28, 100453. [CrossRef]

78. Saaty, T.L.; Özdemir, M.S. How many judges should there be in a group? Ann. Data Sci. 2014, 1, 359-368. [CrossRef]

79. Kendall, M.G.; Gibbons, J.D. (Eds.) Rank Correlation Methods; Oxford University Press: Oxford, UK, 1990.

80. Legendre, P. Species associations: The Kendall coefficient of concordance revisited. J. Agric. Biol. Environ. Stat. 2005, 10, 226. [CrossRef]

81. Shakou, L.M.; Wybo, J.-L.; Reniers, G.; Boustras, G. Developing an innovative framework for enhancing the resilience of critical infrastructure to climate change. Saf. Sci. 2019, 118, 364-378. [CrossRef]

82. Marrone, S.; Nardone, R.; Tedesco, A.; D'Amore, P.; Vittorini, V.; Setola, R.; De Cillis, F.; Mazzocca, N. Vulnerability modeling and analysis for critical infrastructure protection applications. Int. J. Crit. Infrastruct. Prot. 2013, 6, 217-227. [CrossRef]

83. Alcaraz, C.; Zeadally, S. Critical infrastructure protection: Requirements and challenges for the 21st century. Int. J. Crit. Infrastruct. Prot. 2015, 8, 53-66. [CrossRef]

(C) 2020 by the authors. Licensee MDPI, Basel, Switzerland. This article is an open access article distributed under the terms and conditions of the Creative Commons Attribution (CC BY) license (http://creativecommons.org/licenses/by/4.0/). 